\title{
Comparison the sedation effect and satisfaction of two combinations, dexmedetomidine and fentanyl with midazolam and fentanyl, in patients undergoing bronchoscopy
}

\author{
Alireza Kamali', Sepideh Sarkhosh², Hosein Kazemizadeh³
}

'Department of Anesthesiology and Critical Care, Arak University of Medical Sciences, Arak, Iran.

${ }^{2}$ Medical Sciences Research Committee, Arak University of Medical Sciences, Arak, Iran.

${ }^{3}$ Department of Internal Medicine, Arak University of Medical Sciences, Arak, Iran.

Corresponding author: Hosein Kazemizadeh (E-mail: dr.hoseinkazemizadeh@gmail.com )

(Submitted: 02 September 2020 - Revised version received: 19 September 2020 - Accepted: 06 ` October 2020 - Published online: 26 December 2020)

\begin{abstract}
Objectives: The aim of this study was to compare sedative effects of dexmedetomidine and fentanyl with midazolam and fentanyl in patients undergoing bronchoscopy.

Methods: This study was a double-blind randomized clinical trial that was performed on 92 patients who referred to Amir al Momenin Hospital in Arak for bronchoscopy and underwent ASA 1 or 2 underlying grading procedure. Patients were randomly divided into two groups of dexmedetomidine and fentanyl (D) midazolam and fentanyl (M). Primary vital signs including hypertension and arterial oxygen saturation were monitored and recorded. Then, all patients were injected with $2 \mu \mathrm{g} / \mathrm{kg}$ fentanyl as a painkiller and after $3 \mathrm{~min}, 30 \mu \mathrm{g}$ dexmedetomidine in syringe with code A and midazolam $3 \mathrm{mg}$ in syringe with code B were injected to patients by an anesthesiologist. Then, the two groups were compared in terms of pain at injection, conscious relaxation, satisfaction of operation, recovery time, hypotension, and arterial oxygen saturation and drug side effects and data were analyzed by using statistical tests.

Results: There was no significant difference between the two groups in terms of mean age and sex distribution. According to the results of this study, there was no significant difference between the two groups in mean blood pressure (P-value $=0.6)$ and mean heart rate (P-value $=0.4$ ) at the time of bronchoscopy, but at 5 and 10 min after bronchoscopy, there was a significant difference, mean blood pressure and heart rate were significantly lower in dexmedetomidine group.

Conclusion: Both dexmedetomidine and midazolam drug groups contributed to the development of stable and sedative hemodynamics and satisfaction in patients undergoing bronchoscopy, however, the dexmedetomidine and fentanyl group showed a significant decrease in blood pressure and heart rate compared to midazolam and fentanyl and a weaker decrease in arterial oxygen saturation, and patients with bronchoscopy were more satisfied in the dexmedetomidine group.

Keywords: Bronchoscopy, sedation, fentanyl, dexmedetomidine, midazolam.
\end{abstract}

\section{Introduction}

Bronchoscopy is a diagnostic method to treat and observe the airways. A bronchoscope is a device that enters through the nose or mouth and gives the doctor the opportunity to examine abnormalities including foreign bodies, bleeding, tumors, inflammation, and to sample if necessary. The bronchoscope consists of metal tubes with multiple lamps and a camera that displays airway images on the monitor. ${ }^{1}$ Most patients undergoing bronchoscopy, even if local anesthesia and appropriate analgesia are provided during the procedure, see it as a traumatic event. Bronchoscope stimulate the mucosa and imminent suffocation, especially when co-administered with hypoxia, may cause fear and anxiety, and its effect on the cardiovascular system may cause complications such as arrhythmia and myocardial infarction, as well as psychological complications including increased patient anxiety. ${ }^{2-4}$ Since bronchoscopy provides valuable diagnostic information and intervention therapies to specialists, it is also a non-invasive procedure. The necessity to do so is unimaginable, and given that most patients are afraid of the procedure and are uncomfortable or painful to perform, a reliable sedation can relieve anxiety, reduce discomfort, increase satisfaction, and create forgetfulness. ${ }^{5}$ For this reason, the use of sedatives as an inexpensive, safe, and easy method has been considered. These include dexmedetomidine, midazolam, and fentanyl.
Dexmedetomidine is a selective alpha-2 adrenoceptor agonist with high specificity. ${ }^{6}$ This drug has been used as an adjuvant in general anesthesia with a central sympatholytic effect, has helped to stabilize the patient's hemodynamic status and has a potent anesthetic and analgesia effect, ${ }^{7}$ which reduces the need for opioids and their complications ${ }^{8}$ and reduces stress response and improves recovery quality. ${ }^{9}$

Midazolam is a sedative and belong to the benzodiazepines. It has the fastest onset among benzodiazepines (about $30-60 \mathrm{~s}$ ) and is shorter in duration..$^{10}$ Midazolam has various hypnotic, anticonvulsant, and anxiolytic effects as well as a dose-dependent protective effect against cerebral hypoxia. This drug causes a greater drop in blood pressure and a higher respiratory depression than diazepam and lorazepam. ${ }^{11}$

Fentanyl is a fast-starting anesthetic and has a short duration of action. It is an opioid group with a potential of 50-100 times more morphine. It is considered a safe anesthetic drug because of its extensive therapeutic index..$^{12}$ The aim of this study was to compare the sedative and satisfaction effects of bronchoscopy candidiasis with the combination of dexmedetomidine and fentanyl with midazolam and fentanyl.

\section{Material and Methods}

This study is a single-blinded randomized clinical trial in which patients undergoing bronchoscopy referred to Amir 
al Momenin Hospital of Arak - Iran were randomly divided into two equal groups, dexmedetomidine, Fentanyl (D) and Midazolam, Fentanyl (M). All patients entered the study after obtaining informed consent and having inclusion criteria. Inclusion criteria:

1 - Age over 18 and under 70 years.

2 - BMI below $30 \mathrm{~kg} / \mathrm{m}^{2}$

3 - No sedative or anxiolytic use or history of substance abuse.

4 - Pregnancy.

5- Kidney failure.

6 - Neurological disorders.

7 - No sensitivity to midazolam or soy.

8 - No history of heart disease or drug use.

\section{Exclusion criteria:}

1 - Relaxation Level Rating 5.

2 - Ability to drink liquids.

3 - Sitting alone beside the bed.

Before doing the research, patients were described with Visual Analogue Scale (VAS) and a demographic questionnaire with primary vital signs was recorded. Cubital venipuncture was performed and $3 \mathrm{~min}$ before bronchoscopy, $2 \mathrm{mg} / \mathrm{kg}$ fentanyl was given by anesthesiologist and $30 \mathrm{mg}$ dexmedetomidine to the patient 1 min before surgery or midazolam was injected at a dose of $3 \mathrm{mg}$ at random. After 5 and $15 \mathrm{~min}$ from the onset of bronchoscopy and recovery of the patient in terms of blood pressure, heart rate, arterial oxygen saturation with pulse oximeter, and respiratory rate per minute were recorded by the researcher and recorded in a questionnaire.

Sample size:

$$
\begin{gathered}
X=\frac{\left(Z_{1-\frac{\alpha}{2}}+Z_{1-\beta}\right)^{2}\left(\delta_{1}+\delta_{2}\right)^{2}}{\left(\mu_{1}-\mu_{2}\right)^{2}} \\
\sum_{1-\frac{\alpha}{2}}=1.96 \quad \delta_{1}=10 \quad \mu_{1}=29 \\
\mu_{1}=19 \quad \delta_{2}=11 \quad Z_{1-\beta}=1.28 \\
\Rightarrow X=92
\end{gathered}
$$

The number of samples in each group was 46 and 92 in total.

\section{Data analysis}

SPSS software (version 11) was used for data analysis. Mean and standard deviation were used for quantitative data and ANOVA was used for data analysis and if the data were significant, Bonferroni correction was used to find the exact scattering region. $U$-test was used to evaluate qualitative data and Fisher's exact test was used to compare the symptoms.

\section{Ethical considerations}

A written letter was received from respected university officials to introduce them to the research centers. Written letter was obtained from respected authorities of selected research centers. The purpose of the study was described for all research units and their written consent was obtained. All patients' information is kept confidential by the plan's administrator.
In all stages of research, all ethics statements in Helsinki Research and Research Committees in Arak University of Medical Sciences were considered. This research has a code of ethics IR.ARAKMU.REC. 1396.241.

\section{Results}

92 patients undergoing bronchoscopy were randomly divided into two equal groups. In Chart 1, patients undergoing bronchoscopy in two groups of dexmedetomidine, fentanyl and midazolam, fentanyl were evaluated for age and sex and no significant difference was observed between the two groups in terms of mean age. The mean age of the patients was similar in both groups (P-value $=0.6$ ), and there was no significant difference between the two groups in terms of sex distribution and the frequency of males in both groups was $65 \%$.

Table 1 compares the changes in mean blood pressure of patients undergoing bronchoscopy at baseline, 5 and $10 \mathrm{~min}$ after initiation in the two groups. According to the results, there was no significant difference between the two groups regarding mean blood pressure at the time of initiation bronchoscopy (P-value $=0.6$ ), but at 5 and $10 \mathrm{~min}$ after bronchoscopy, there was a significant difference and mean blood pressure was significantly lower in dexmedetomidine group $(\mathrm{P}$-value $=0.04, \mathrm{P}$-value $=0.03)$.

Changes in mean heart rate of patients undergoing bronchoscopy at baseline, 5 and $10 \mathrm{~min}$ after initiation were assessed in the two groups; dexmedetomidine + fentanyl and midazolam + fentanyl. Mean PR at baseline in the two groups were $93.5 \pm 5.3$ and $95.4 \pm 4.9$, mean PR at 5 min after start in

\begin{tabular}{|c|c|c|c|}
\hline P-value & $\begin{array}{l}\text { Midazolam + } \\
\text { Fentanyl } \\
\text { (Group M) }\end{array}$ & $\begin{array}{c}\text { Dexmedetomidine + } \\
\text { Fentanyl } \\
\text { (Group D) }\end{array}$ & Average / Group \\
\hline$P=0.6$ & $5.8 \pm 109.9$ & $6.9 \pm 107.8$ & $\begin{array}{c}\text { Average MAP at } \\
\text { base time }\end{array}$ \\
\hline$P=0.04$ & $7.9 \pm 107.7$ & $4.9 \pm 95.8$ & $\begin{array}{l}\text { Average MAP } \\
\text { after } 5 \text { minutes }\end{array}$ \\
\hline$P=0.03$ & $9.7 \pm 111.1$ & $6.7 \pm 99.7$ & $\begin{array}{l}\text { Average MAP } \\
\text { after } 10 \text { minutes }\end{array}$ \\
\hline
\end{tabular}

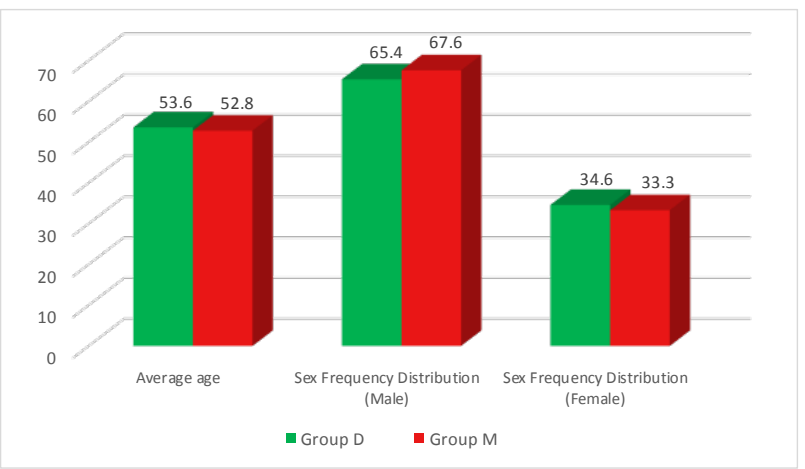

Chart 1 Comparison of age and sex of patients undergoing bronchoscopy. 
the two groups were $89.3 \pm 4.8$ and $96.5 \pm 3.8$, respectively, and mean PR of the two groups after $10 \mathrm{~min}$ of initiation was $90.4 \pm 5.9$ and 105.4 \pm 8.6 , respectively. According to the results, no significant difference was observed between the two groups in terms of mean heart rate at the initiation of bronchoscopy (before the procedure) $(\mathrm{P}$-value $=0.4)$ but there was a significant difference at 5 and 10 min after the start of bronchoscopy. The mean heart rate was significantly lower in the dexmedetomidine group $(\mathrm{P}$-value $=0.04, \mathrm{P}$-value $=0.03)$

Comparison of mean arterial oxygen saturation changes in patients undergoing bronchoscopy at baseline, 5 and 10 min after starting in the two groups is discussed in Table 2. According to the results between the two groups in terms of mean arterial oxygen saturation of patients at different times onset of bronchoscopy (before surgery) and 5 and $10 \mathrm{~min}$ after bronchoscopy, no significant difference was observed (P-value $=0.4$, P-value $=0.2$ ).

Fig. 2 compares sedation score of patients undergoing bronchoscopy at 5, 10, 15 and 20 min after initiation of bronchoscopy in two groups of dexmedetomidine + fentanyl and midazolam + fentanyl. According to the results, there was no significant difference between the two groups in terms of sedation score at 5, 10, 15 and 20 min after the initiation of bronchoscopy $(\mathrm{P}$-value $=0.4, \mathrm{P}$-value $=0.6)$.

Comparison of satisfaction score and Ramsay score in recovery of bronchoscopy candidates in two groups in Table 3 was evaluated. According to the results, there was a significant difference between the two groups in terms of patient satisfaction score in recovery, there was a significant difference in dexmedetomidine patients' satisfaction (P-value $=0.04)$, but there was no significant difference between the two groups Ramsay score in the recovery and were almost the same $(P$-value $=0.6)$.

\begin{tabular}{|c|c|c|c|}
\hline P-value & $\begin{array}{l}\text { Midazolam } \\
\text { + Fentanyl } \\
\text { (Group M) }\end{array}$ & $\begin{array}{c}\text { Dexmedetomidine + } \\
\text { Fentanyl (Group D) }\end{array}$ & Average / Group \\
\hline$P=0.4$ & $3.7 \pm 93.4$ & $5.2 \pm 94.4$ & $\begin{array}{c}\text { Average spo2 at } \\
\text { base time }\end{array}$ \\
\hline$P=0.4$ & $4.9 \pm 92.7$ & $2.8 \pm 93.9$ & $\begin{array}{l}\text { Average spo } 2 \\
\text { after } 5 \text { minutes }\end{array}$ \\
\hline$P=0.2$ & $3.6 \pm 91.8$ & $4.8 \pm 93.1$ & $\begin{array}{c}\text { Average spoz } \\
\text { after } 10 \text { minutes }\end{array}$ \\
\hline
\end{tabular}

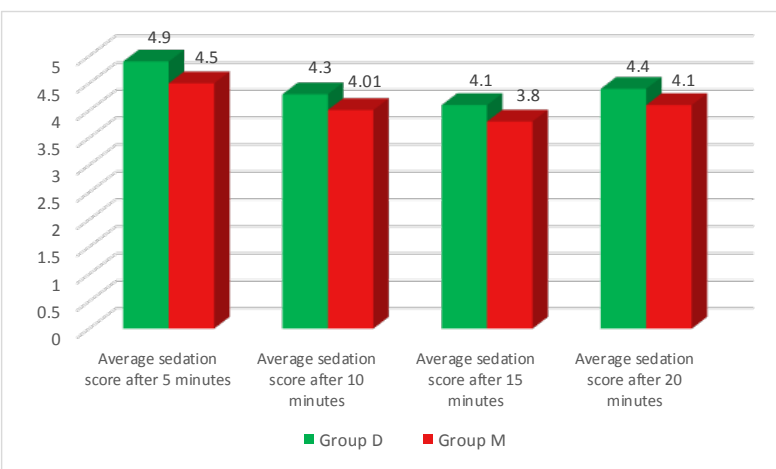

Fig. 2 Comparison of sedation score.

\begin{tabular}{|c|c|c|c|}
\hline P-value & $\begin{array}{c}\text { Midazolam + } \\
\text { Fentanyl } \\
\text { (Group M) }\end{array}$ & $\begin{array}{l}\text { Dexmedetomidine } \\
\text { + Fentanyl } \\
\text { (Group D) }\end{array}$ & Average / Group \\
\hline$P=0.04$ & $0.76 \pm 1.66$ & $0.98 \pm 2.8$ & $\begin{array}{c}\text { Average } \\
\text { satisfaction score } \\
\text { in recovery }\end{array}$ \\
\hline$P=0.6$ & $0.98 \pm 4.7$ & $1.1 \pm 4.85$ & $\begin{array}{l}\text { Average Ramsay } \\
\text { score in recovery }\end{array}$ \\
\hline
\end{tabular}

\section{Discussion}

Bronchoscopy is a safe procedure and is often performed to evaluate, diagnose, and treat patients with respiratory diseases. ${ }^{13}$ Bronchoscopy is used as a diagnostic and therapeutic method for the examination of pulmonary diseases, tumors, chronic cough, and respiratory tract infections. This requires a short-term sedation that allows the patient to tolerate an invasive procedure while maintaining cardiorespiratory function. ${ }^{14}$ The aim of this study was to compare the sedative and satisfaction effects of dexmedetomidine + fentanyl and midazolam + fentanyl in patients undergoing bronchoscopy. No significant differences were observed between the two groups in terms of mean age and sex distribution and mean age of the patients was same in both groups. According to the results of this study, there was no significant difference between the two groups regarding mean blood pressure $(\mathrm{P}$-value $=0.6)$ and mean heart rate $(\mathrm{P}$-value $=0.4)$ at the time of bronchoscopy, but at 5 and $10 \mathrm{~min}$ after bronchoscopy, there was a significant difference, mean blood pressure and heart rate were significantly lower in dexmedetomidine group.

In this study, no significant difference was observed in the mean arterial oxygen saturation of patients at different times of onset bronchoscopy and 5 and $10 \mathrm{~min}$ after bronchoscopy. There was no significant difference between the two groups in the score of sedation at 5, 10, 15 and 20 min after the initiation of bronchoscopy. According to the results, there was a significant difference between the two groups in terms of patients satisfaction score in recovery and there was a significant difference in patients satisfaction score in dexmedetomidine group $(P$-value $=0.04)$, but Ramsay score showed no significant difference between the two groups in recovery and was almost the same $(\mathrm{P}$-value $=0.6)$.

A number of similar studies have been undertaken, including Derek's 2010 study at the department of anesthesiology at Haydarpasa Teaching Hospital, Turkey, with the aim of comparing dexmedetomidine and midazolam for sleep, pain, and control of hemodynamic symptoms during colonoscopy under sedation performed on 40 patients (ASA I or II, aged from 20 to 80 years). Dexmedetomidine create more stable hemodynamics, higher Ramsay score, greater patient satisfaction, and lower numeric rating scale in colonoscopy patients. As a result of this study, dexmedetomidine can be used as a safe sedative in colonoscopy. ${ }^{15}$ The results of this study were consistent with our study. In our study, dexmedetomidine resulted in more stable hemodynamics and higher Ramsay score and more satisfaction. 
Another study by Demirany in 2007 at the Abant Izzet Baysal University Anesthesiology Department in Turkey, comparing dexmedetomidine and midazolam in sedation of patients undergoing upper endoscopy, It was concluded that dexmedetomidine is a safe drug for sedation in patients with upper gastroscopy and is better than midazolam in terms of side effects and endoscopic satisfaction. As a result, dexmedetomidine is a better drug than midazolam. ${ }^{16}$ The results of this study were consistent with our study that dexmedetomidine was a safe drug for sedation in patients undergoing bronchoscopy and was superior to midazolam in adverse effects and satisfaction.

Finally, in a similar study by Cheung in 2007, patients were compared with dexmedetomidine and midazolam in the surgical relaxation of molar lesions. There was no significant difference between satisfaction and pain quality, and midazolam caused more amnesia. Patients and surgeons satisfaction was similar in the two groups so that patients were satisfied with the same procedure in the future, but heart rate and blood pressure were lower in the dexmedetomidine group during surgery. ${ }^{17}$ The results of our study were consistent with this study, but this part of the study contradicted our study with significant differences in patient satisfaction and pain quality. But eventually more satisfaction was found in the dexmedetomidine group, which was similar to our study.

\section{Conclusion}

According to the results of this study, it can be concluded that in both groups, dexmedetomidine and midazolam were involved in the development of stable and sedative hemodynamics and satisfaction of patients with bronchoscopy. But the dexmedetomidine and fentanyl group had higher drop blood pressure and heart rate and lower drop arterial oxygen saturation compared to midazolam and fentanyl. And patients with bronchoscopy were more satisfied in the dexmedetomidine group. Finally, it is suggested that similar studies with larger sample sizes as well as comparisons of other sedatives be conducted in different processes.

\section{Conflict of Interest}

None

\section{References}

1. Kubba H, Cooke J, Heartly B. Can we develop a protocol for the safe decannulation of tracheostomies in children less than 18 months old? Int J Pediatr Otorhinolaryngol. 2004;6(8):935-937.

2. Mitchell RB, Hussey HM, Setzen G, Jacobs IN, Nussenbaum B, Dawson C, Brown CA, Brandt C, Deakins K, Hartnick C, et al. Clinical consensus statement: tracheostomy care. Otolaryngol Head Neck Surg. 2013;14(8):6-9.

3. Cristea I, Baker CD. Ventilator weaning and tracheostomy decannulation in children: more than one way. Pediatric Pulmonol. 2016;5(1):773-774.

4. Cabrini L, Gioia L, Gemma M, Melloni G, Carretta A, Ciriaco P, et al. Acupuncture for diagnostic fiber optic bronchoscopy: a prospective, randomized, placebo-controlled study. Am J Chin Med. 2006;34(3):409-15.

5. Simma B, Spehler D, Burger R, Uehlinger J, Ghelfi D, Dangel P, Hof E, Fanconi S. Tracheostomy in children. Eur J Pediatr.1996;15(3):291-296.

6. Savola JM, Ruskoaho H, Puurunen J, Salonen JS, Karki NT. Evidence for medetomidine as a selective and potent agonist at alpha 2-adrenoreceptors. J Auton Pharmacol. 1986;6(3):275-84.

7. Gurbet A, Basagan-Mogol E, Turker G, Ugun F, Kaya FN, Ozcan B. Intraoperative infusion of dexmedetomidine reduces perioperative analgesic requirements. Can J Anaesth. 2006;53(5):646-52.

8. Blaudszun G, Lysakowski C, Elia N, Tramer MR. Effect of perioperative systemic alpha2 agonists on postoperative morphine consumption and pain intensity: systematic review and meta-analysis of randomized controlled trials. Anesthesiology. 2012;116(4):1312-22.

9. Bekker A, Haile M, Kline R, Didehvar S, Babu R, Martiniuk F, Urban M. The effect of intraoperative infusion of dexmedetomidine on the quality of recovery after major spinal surgery. J Neurosurg Anesthesiol. 2013;25(1):16-24.

10. Anand KJ, Barton BA, Mclntosh N. Analgesia and sedation in preterm neonates who require ventilatory support: results from the NOPAIN trial. Neonatal Outcome and Prolonged Analgesia in Neonates. Arch Pediatr Adolesc Med. 1999;153(4):331-338.

11. Anand KJ, Hall RW, Desai N. Effects of morphine analgesia in ventilated preterm neonates: primary outcomes from the NEOPAIN randomised trial. Lancet. 2004;363(9422):1673-1682.

12. Qu W, Rippe RA, Ma J, Scarborough P, Biagini C, Fiedorek FT, et al. Nutritional status modulates rat liver cytochrome P450 arachidonic acid metabolism. Mol Pharmacol. 1998:54(3):504-513.

13. Du Rand I, Blaikley J, Booton R, Chaudhuri N, Gupta V, Khalid S, et al. British Thoracic Society guideline for diagnostic flexible bronchoscopy in adults. Thorax. 2013;6(8):1-4.

14. Kremer B, Botos-Kremer Al, Eckel HE, Schlondorff G. Indications, complications and surgical techniques for pediatric tracheostomies an update. J Pediatr Surg. 2002;3(7):1556-1562.

15. Dere K, Sucullu I, Budak ET, Yeyen S, Filiz Al, Ozkan S, Dagli G. A comparison of dexmedetomidine versus midazolam for sedation, pain and hemodynamic control, during colonoscopy under conscious sedation. Eur J Anaesthesiol. 2010;27(7):648-52.

16. Demiraran Y, Korkut E, Tamer A, Yorulmaz I, Kocaman B, Sezen G, Akcan Y. The comparison of dexmedetomidine and midazolam used for sedation of patients during upper endoscopy: A prospective, randomized study. Can 」 Gastroenterol. 2007;21(1):25-9.

17. Cheung CW, Ying CLA, Chiu WK, Wong GTC. A comparison of dexmedetomidine and midazolam for sedation in third molar surgery. 2007;6(2):1132-1138.

This work is licensed under a Creative Commons Attribution-NonCommercial 3.0 Unported License which allows users to read, copy, distribute and make derivative works for non-commercial purposes from the material, as long as the author of the original work is cited properly. 